\title{
Dynamics of gaps and large openings in a secondary forest of Northeast China over 50 years
}

\author{
Chunyu Zhu ${ }^{1,2,3} \cdot$ Jiaojun Zhu ${ }^{1,2} \cdot$ G. Geoff Wang ${ }^{4}$. Xiao Zheng ${ }^{1,2} \cdot$ Deliang Lu ${ }^{1,2,3} \cdot$ Tian Gao ${ }^{1,2}$
}

Received: 6 July 2018 / Accepted: 30 April 2019 /Published online: 9 July 2019

(C) INRA and Springer-Verlag France SAS, part of Springer Nature 2019

\begin{abstract}
- Key message The gap dynamics in the studied secondary forest were comparable to those of other temperate forests; large openings were filled within 30 years by afforestation; large and medium gaps closed 30-40 years after they formed. - Context Gaps have important roles in forest regeneration and plant succession. However, it is difficult to determine gap dynamics over long time periods at regional scales.

- Aims We studied how the dynamics of gaps and large openings (oversized "gaps") changed in a secondary temperate forest over 50 years.

- Methods We computed the dynamic indices of gaps $\left(16-3257 \mathrm{~m}^{2}\right)$ and large openings $\left(>3257 \mathrm{~m}^{2}\right)$ using remote sensing techniques applied to six satellite images that were taken approximately every 10 years. Additionally, number-based gap closure ratios were calculated at each interval.

- Results Gap dynamics were comparable in magnitude to those calculated for other temperate forests, and $60 \%$ and $53 \%$ of the large and medium gaps had closed within 30-40 and 20-30 years, respectively. The small gaps closed within 10 years, based on ground-level surveys, and 79.2\% of large openings that existed in 1964 were covered by artificial forests in 1994 .

- Conclusion Gaps of different sizes closed within 40 years due to natural regeneration. Large openings had closed within 30 years via afforestation. These findings can be used for evaluating recovery status and for predicting succession times in secondary forest structures driven by gap formation.
\end{abstract}

Keywords Secondary forest $\cdot$ Gap pattern $\cdot$ Gap duration time $\cdot$ Anthropogenic opening

\section{Introduction}

Handling Editor: Laurent Bergès

Contribution of the co-authors Jiaojun Zhu and G. Geoff Wang designed experiments; Chunyuzhu and Deliang Lu carried out experiments; Chunyuzhu and Xiao Zheng analyzed experimental results; Tian Gao assisted with remote sensing technology; Chunyu zhu and Jiaojun Zhu wrote the manuscript.

Jiaojun Zhu

jiaojunzhu@iae.ac.cn

1 CAS Key Laboratory of Forest Ecology and Management, Institute of Applied Ecology, Chinese Academy of Sciences,

Shenyang 110016, China

2 Qingyuan Forest CERN, Chinese Academy of Sciences, Shenyang 110016, China

3 Graduate University of Chinese Academy of Sciences, Beijing 100049, China

4 School of Agricultural, Forest and Environmental Sciences, Clemson University, Clemson, SC 29634-0317, USA
The gap phase initiates the forest development cycle and is dominated by tree regeneration (Watt 1947). Thus, it plays an important role in the establishment, survival, and development of tree species with diverse ecological requirements (Runkle 1989; Ritter et al. 2005; Petritan et al. 2013). Gap formation increases the availability of resources for plant growth, such as light, temperature, and soil moisture, thereby influencing sapling recruitment and growth patterns (Ritter et al. 2005; Raymond et al. 2006; Sapkota et al. 2009; Muscolo et al. 2014). Tree species composition and forest structure are functions of the sizes, shapes, ages, and temporal shifts of forest gaps (Blackburn 2014). Hence, quantifying gap disturbance regimes through space and time provides useful tools for evaluating the current forest status and for predicting future dynamics (Elias and Dias 2009).

Gap characteristics have been described across a range of different forests. Most descriptions provide information on gap fraction (areal proportion of gaps in the forest), gap 
number, and gap size distribution (Runkle 1982; Fujita et al. 2003). However, information on gap dynamics derived from repeated observations of individual stands is sparse (Kenderes et al. 2008). More comprehensive quantitative information on canopy gap dynamics is required for improving understanding of forest disturbance and canopy dynamics. Such data will substantially aid in the development of forest management plans.

The cyclical process of gap dynamics from creation through infilling by lateral crown growth or tree regeneration and the subsequent formation of new gaps are crucial elements of autogenic succession (Muscolo et al. 2014). Gap dynamics are usually quantified by measuring the rates of gap formation and closure, as well as the duration of gap persistence (Vepakomma et al. 2012). However, gap dynamics changed with forest characteristics, such as the successional stage, disturbance resistance, canopy height, and tree growth rate (Vepakomma et al. 2008; Kathke and Bruelheide 2010; Sefidi et al. 2011; Muscolo et al. 2014; Zhu et al. 2017). For example, gap formation rates reported by Henbo et al. (2004) for an old-growth beech forest were $0.5-1.3 \%$ of forested area per year, which were four times higher than rates in a near-natural spruce forest reported by Kathke and Bruelheide (2010). Bartemucci et al. (2002) indicated that the gap closure rates in temperate forests were usually more rapid than those in boreal forests, but contradictory results have been published (Vepakomma et al. 2012; Rugani et al. 2013). Thus, gap dynamics should be studied in different forest ecosystems.

Secondary forests comprise the major component of Chinese timber resources and have received considerable attention in recent years (Zhu et al. 2007). The primary forests were largely ( $>70 \%$ ) converted to secondary stands over the past century through anthropogenic disturbances (Zhu et al. 2017). To improve the ecosystem services of forests, most of the secondary stands in northeastern China were converted into non-commercial forest ecosystems in 1998, under the auspices of the Natural Forest Protection Project (Li et al. 2005). Retrospective studies of canopy gap dynamics over the long term would provide useful information for evaluating the restoration of disturbed forests in this region and for understanding the regeneration process and the mechanisms underlying gap dynamics.

Large openings-i.e., above the size limit for gaps proposed by Zhu et al. (2015) - differ from gaps in terms of their driving factors and means of closure. However, the dynamics of large openings also need to be estimated like gaps in secondary forests, because (1) large openings and gaps are similar in terms of previous land use and (2) during the past 50 years, management practices, including tree plantation and logging, have created an artificial forest cycle consisting of large openings, growth, and mature phases, which has played a similar role to gaps in the recovery of secondary forest ecosystems.

Traditionally, the data required for describing gap characteristics have been provided by ground-level field surveys, which do not adequately capture spatial and temporal patterns across large regions (Yamamoto et al. 2011). Remote sensing is an alternative method for studying the characteristics of gap dynamics at landscape levels (Baumann et al. 2014). Highresolution satellite remote sensing data are able to provide more detailed and comprehensive information about canopy gaps over larger space and time scales than field surveys can offer (Garbarino et al. 2012). However, this useful satellite method has rarely been used to provide data on the longterm dynamics of canopy gaps for temperate secondary forests.

The objective of our study was to analyze canopy the dynamics of gaps and large openings in a temperate secondary forest over a 50-year period (1964, 1974, 1986, 1994, 2003 and 2014). We hypothesized that small gaps would account more for overall gap dynamics and close faster than larger ones.

\section{Materials and methods}

\subsection{Study area}

The study was conducted at the Qingyuan Forest Ecosystem Research Station, which is an approved member of the Chinese Ecosystem Research Network (CERN), a component of the Chinese Academy of Sciences (CAS). The station is within Qingyuan County, a montane region in eastern Liaoning Province, northeastern China $\left(41^{\circ} 51^{\prime} 6.1^{\prime \prime} \mathrm{N}\right.$, $124^{\circ} 54^{\prime} 32.6^{\prime \prime} \mathrm{E}$ ) (Fig. 1). The region has a continental monsoon climate with long, cold winters and hot, rainy summers. The annual precipitation is $700-850 \mathrm{~mm}, 80 \%$ of which falls in June and August. The mean annual temperature is $4.7^{\circ} \mathrm{C}$, with an annual minimum of $-37.6{ }^{\circ} \mathrm{C}$ and an annual maximum of $36.5^{\circ} \mathrm{C}$. The soil is a typical brown soil that belongs to Udalfs. The average frost-free period is 130 days. The average tree canopy height at the time of this study was $20 \mathrm{~m}$ (Zhu et al. 2007).

The study site was originally dominated by old-growth, mixed broadleaf/Korean pine forests until the 1930s. However, the original forests were gradually replaced by secondary forests after decades of timber harvesting and massive anthropogenic disturbances. To meet the timber demand, some of the secondary forests were logged and replaced by larch (Larix spp.) plantations after the 1960s (Zhu et al. 2017). Our study site comprised a typical temperate secondary forest ecosystem after 50 years of exploitation: a mixture of secondary forest and larch plantations. The nearest late-successional forest is located in Changbai Mountains of northeastern 
Fig. 1 Location of the study area (QFCERN: Qingyuan forest CERN)

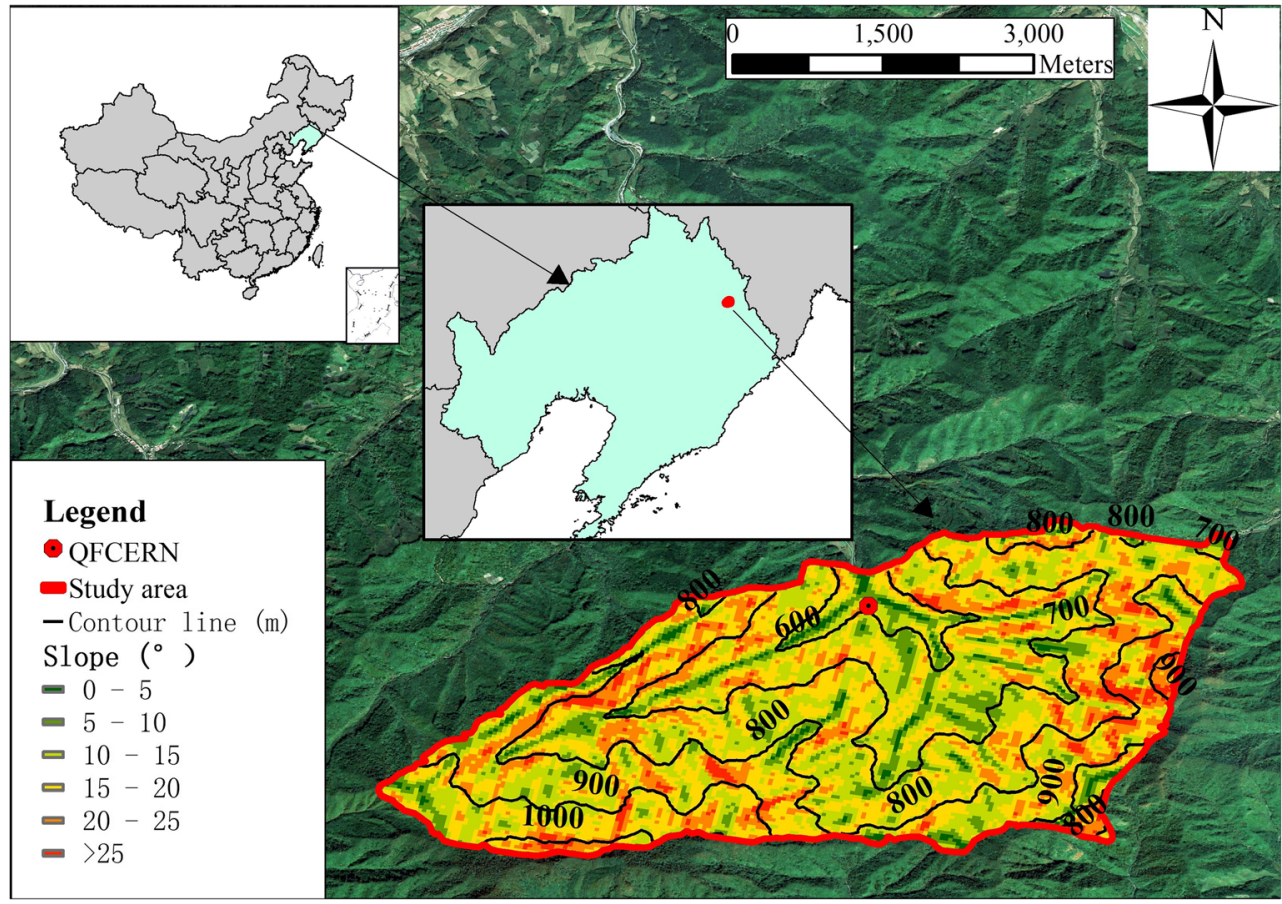

China, which is more than $200 \mathrm{~km}$ away from our study site. The main components of the typical forest stands are now (2014) Fraxinus rhynchophylla Hance, Juglans mandshurica Maxim., Phellodendron amurense Rupr., Quercus mongolica Fisch. ex Ledeb. (Yan et al. 2010).

From 1964 to 2014, the local forestry administration managed the secondary forest in three main ways: afforestation, tending, and clear cutting. Clear cutting removed all trees in the forest compartments and accounted for only $0.51 \%$ of the study area. It had a slight impact on the formation of large openings but little impact on the formation of gaps. Tending was conducted in $6.47 \%$ of the study area and involved removing weak individual trees from dense forest stands. Minor spaces (up to the size of small gaps) would have opened up and then disappeared within 10 years ( $\mathrm{Lu}$ et al. 2015). Therefore, we can conclude that less than $7 \%$ of the gaps resulted from tending within a 10 -year period; i.e., more than $93 \%$ of gaps formed naturally. Afforestation was conducted in
$8.91 \%$ of the total area, mostly in existing large openings rather than gaps, because afforestation efforts had a minimum size of 2 ha, which far exceeds the upper limit ( $0.3 \mathrm{ha})$ of gaps (Table 1). Thus, we can reasonably infer that the gaps in the study were mainly formed and closed by natural disturbances, whereas the filling of large openings was closely related to artificial disturbances.

\subsection{Image collection and pre-processing}

The satellite images used in this study were taken every 10 years over a 50-year period, allowing comparisons among five consecutive time periods of similar duration (basic image information is listed in Table 2). The spatial resolution of all images used to classify medium and large gaps was unified to $10 \mathrm{~m}$, while small gaps were classified with a resolution of $3 \mathrm{~m}$ in the images from 1964, 1976, 2003 and 2014. The images were cloud-free and were taken from June to September. The
Table 1 The area fraction of the forest with different management practices in different periods

\begin{tabular}{llll}
\hline Periods & \multicolumn{2}{l}{ Area fraction of the forest with different management practices $(\%)$} \\
\cline { 2 - 4 } & Tending & Clear cutting & Afforestation \\
\hline $1964-1976$ & 2.55 & 0.51 & 4.28 \\
$1977-1986$ & 1.12 & 0 & 2.85 \\
$1987-1994$ & 2.80 & 0 & 1.53 \\
$1995-2003$ & 0 & 0 & 0.25 \\
$2004-2014$ & 0 & 0 & 0 \\
Total & 6.47 & 0.51 & 8.91 \\
\hline
\end{tabular}


Table 2 The basic information for the images used in this analysis

\begin{tabular}{llll}
\hline Year & Month & Source & Spatial resolution \\
\hline 1964 & July & KEYHOLE-7 & Panchromatic 2 m \\
1976 & June & KEYHOLE-12 & Panchromatic $3 \mathrm{~m}$ \\
1986 & July & SPOT 1 & Panchromatic $10 \mathrm{~m}$ \\
1994 & September & SPOT 2 & Panchromatic $10 \mathrm{~m}$ \\
2003 & July & SPOT 5 & Panchromatic $2.5 \mathrm{~m}$ \\
2014 & August & KOMPSAT-3 & Panchromatic $0.7 \mathrm{~m} ;$ Multispectral $2.8 \mathrm{~m}$ \\
\hline
\end{tabular}

nominal values of Gain and Offset were used to process surface reflectance in the images, and a dark subtraction algorithm was applied for atmospheric correction using ENVI software (Garbarino et al. 2012). Subsequently, 20-30 uniformly distributed ground control points (derived from a 1:5000 topographic map of the study area) were used for georeferencing and orthorectifying the images (Yan et al. 2011). The root-mean-square error (RMSE) of the geometric rectification across all images was less than one pixel.

\subsection{Gap identification and classification}

First, we identified gaps using the unsupervised classification proposed by Garbarino et al. (2012). The images were classified into 10 classes based on the maximum likelihood decision rule. Then, the 10 classes were aggregated into 5 classes using the Jeffries-Matusita separability test. The resulting five classes were determined according to gaps, rivers, and vegetation types based on visual interpretation and field investigation. The classified images were then simplified into binary images comprising 'gap' pixels and 'non-gap' pixels. The Clump, Eliminate, and Recoding commands in Erdas 2013 (Baumann et al. 2014) were used to optimize the classification results. The accuracy of the classification results was examined using the Accuracy Assessment feature in Erdas 2013. We randomly produced 50 points from each of the classes and positioned each by hand. Subsequently, we calculated the Kappa statistics for the entire classification (Baumann et al. 2014). Kappa coefficients in the range of $0.6-0.8$ were benchmarked as "substantial" (Landis and Koch 1977) and reclassification was necessary when the results failed to pass the threshold of $\mathrm{K}>0.6$. Reclassification ensured that accuracy was appropriate for adequate interpretation of the forest gaps.

\subsection{Field data collection}

To ground-truth the results of our identification and classification, we performed two field investigations. In the first investigation, we conducted a field survey using the belt transect method during August and September of 2014, when we recorded 197 forest gaps. These gaps were positioned on the images by their global positioning system (GPS) coordinates (differential GPS; Unistrong MG868S hardware). Among the recorded gaps, $97.5 \%$ were classified correctly to the nonforest class by visual inspection. The second field investigation was conducted during July and September of 2015. We chose 60 gaps identified from images at different times. We used differential GPS (Unistrong MG868S hardware) to track these image-interpreted gaps in the field by their center coordinates. Five dominant trees in each "gap" were chosen to represent the regeneration layer. Subsequently, the imageinterpreted gaps were considered real gaps when regenerating trees did not reach more than two-thirds of the average canopy tree height. The heights of these trees were measured with a laser rangefinder (Nikon, Forestry Pro550). This second field investigation indicated 60 image-interpreted gaps, of which $86.7 \%$ were real gaps and $13.3 \%$ were closed forests.

\subsection{Calculation of gap dynamic indices}

The non-forest patches were classified into small, medium and large gap categories by the ratio of gap diameter to the mean height of gap border trees $\left(\mathrm{R}_{\mathrm{D} / \mathrm{H}}\right)$; the $\mathrm{R}_{\mathrm{D} / \mathrm{H}}$ ratios of the small, medium, and large gaps were $0.23-0.74,0.74-1.73$, and 1.74 3.23, respectively (Zhu et al. 2015). ArcGIS software analysis tools were used to determine areas of polygons. The mean height of the forest canopy in our study area was $20 \mathrm{~m}$ (measured in the field). We then transformed the $\mathrm{R}_{\mathrm{D} / \mathrm{H}}$ ranges to gap size ranges: $16-172 \mathrm{~m}^{2}$ (small gaps), 172-940 $\mathrm{m}^{2}$ (medium gaps) and 940-3278 $\mathrm{m}^{2}$ (large gaps).

We extracted the gap fraction (proportion of the study area with gaps), gap number, and mean gap size across all observation years using the Calculate Geometry tool in ArcGIS 10.2 software. However, data for the small gaps were lacking in 1986 and 1994 due to the low image resolution (10 m). Subsequently, areabased indices, including gap formation rates (GFR, area that had transformed annually from forest to gap matrix in relation to the total study area) and gap closure rates (GCR, area that had transformed annually from gap to forest matrix in relation to the total study area), were estimated from changes in the grid cells with different canopy states between two time periods (1964-1976 and 2003-2014) (Henbo et al. 2004). To assess the duration of large and medium gaps, we performed an analysis of transitions 
Fig. 2 Spatial patterns of gaps and vacant land in a 1964, b

1976, c 1986, d 1994, e 2003 and f 2014

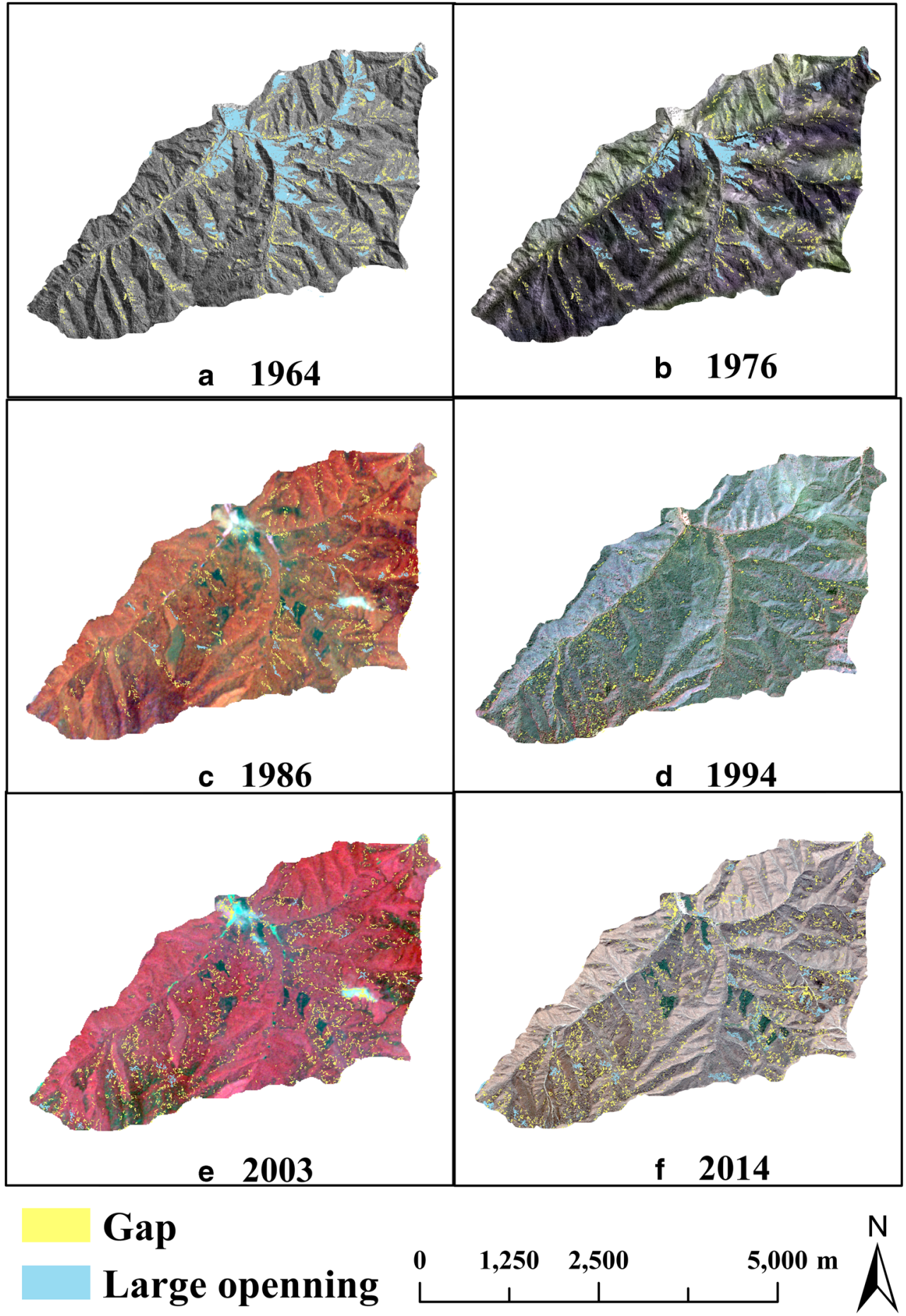

(gap or closed forest matrix) for each large or medium gap (Kathke and Bruelheide 2010) that was newly formed during the periods 1964-1976, 1977-1986, 1987-1994, and 19952003. The number-based gap closure ratios were calculated at each following interval of roughly 10 years (8-12 years). We considered both the initial gap size and that when the gap closed completely. Gaps that partially closed at the end of a time period were assigned to the unclosed-gap group and were not considered when calculating the number-based gap-closure percentage.

\section{Results}

The general characteristics of forest gap dynamics reflected high variability between different years, but we detected no clear temporal trends across the span of the study (Fig. 2, Table 3). The maximum values of gap fraction, gap number, and mean gap size were obtained in 2003; minimum values for these parameters were obtained in 2014 (Table 3). In 1964 1976, 2003 and 2014, most of the gaps are small gaps $(86.1 \%$ 
Table 3 Fraction, number and mean size of large, medium-sized and small gaps in different observation years

\begin{tabular}{|c|c|c|c|c|c|c|c|}
\hline Characteristic & Class & 1964 & 1976 & 1986 & 1994 & 2003 & 2014 \\
\hline \multirow[t]{4}{*}{ Gap fraction $(\%)$} & Large gap & 0.3 & 1.3 & 1.8 & 0.7 & 0.5 & 0.6 \\
\hline & Medium gap & 1.5 & 0.9 & 1.3 & 1.4 & 1.9 & 0.7 \\
\hline & Small gap & 2.0 & 1.9 & $-{ }^{\mathrm{a}}$ & - & 2.7 & 1.3 \\
\hline & Total & 3.8 & 4.1 & - & - & 5.1 & 2.6 \\
\hline \multirow[t]{4}{*}{ Gap number } & Large gap & 33 & 81 & 164 & 59 & 50 & 35 \\
\hline & Medium gap & 647 & 524 & 342 & 457 & 691 & 231 \\
\hline & Small gap & 4369 & 4012 & - & - & 4578 & 4257 \\
\hline & Total & 5049 & 4617 & - & - & 5319 & 4523 \\
\hline \multirow[t]{4}{*}{ Mean gap size /SD $\left(\mathrm{m}^{2}\right)$} & Large gap & $1227 / 420$ & $2167 / 514$ & $1482 / 473$ & $1601 / 443$ & $1350 / 354$ & $2314 / 505$ \\
\hline & Medium gap & $313 / 121$ & $231 / 104$ & $513 / 375$ & $413 / 106$ & $371 / 175$ & $409 / 253$ \\
\hline & Small gap & $62 / 51$ & $64 / 45$ & - & - & $80 / 57$ & $41 / 27$ \\
\hline & Total & $101 / 195$ & $120 / 145$ & - & - & $129 / 117$ & $74 / 231$ \\
\hline
\end{tabular}

${ }^{\mathrm{a}}$ No data were obtained from images because of low resolution $(10 \mathrm{~m})$

in 2003 to $92 \%$ in 2014), representing half of the gap area (46.3\% in 1976 to $52.6 \%$ in 1964). Medium gaps accounted for the second-highest percentage of the gap area in 1964, 2003 and 2014 (average 34.6\%) but large gaps get the ranking in 2014 with a percentage of $31.7 \%$ in 1976 (Fig. 3). The rates of gap formation and gap closure were $0.12 \%$ year $^{-1}$ and $0.10 \%$ year $^{-1}$, respectively, during 1964-1976 and $0.14 \%$ year $^{-1}$ and $0.37 \%$ year $^{-1}$, respectively, during 2003-2014 (Fig. 4). The areal proportion of vacant land declined from $11.1 \%$ in 1964 to $1.1 \%$ in 2014 (Fig. 5), of which 79.2\% was filled with larch (Larix spp.) plantations (Table 4). The cumulative percentage of gap closure data showed that $100 \%$ of gaps were closed after 40 years. For each period, the majority $(52.3-64.5 \%)$ of large gaps closed within 30-40 years, while the majority (47.2$57.9 \%$ ) of medium gaps closed within 20-30 years (Fig. 6).

\section{Discussion}

We compared our gap dynamics indices with those reported for other temperate forests (summarized in Table 4). In general, the

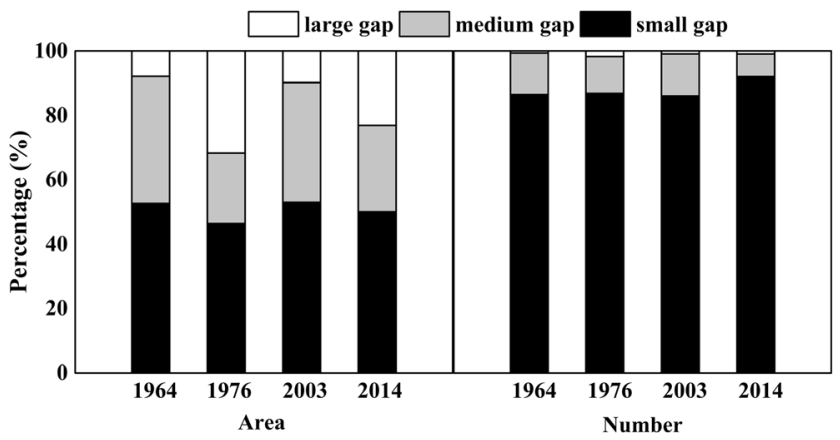

Fig. 3 Area and number ratio of small, medium and large gaps to total gaps in different observation years gap formation rate, gap closure rate, gap fraction, gap number, and mean gap size in our study were within the range of other studies. For example, the gap formation rate of $0.1-0.2 \%$ year $^{-1}$ measured in our study was comparable to those reported by Holeksa and Cybulski (2001) and Kathke and Bruelheide (2010) for near-natural coniferous forests. Other studies have reported much higher dynamic rates. Tanaka and Nakashizuka (1997) measured gap formation rates in an old-growth temperate forest that were approximately four times higher than ours. The wide range of gap dynamic indices for temperate forests may be explained as follows. (1) Gap dynamics are closely associated with the frequency and severity of exogenous disturbances. Henbo et al. (2004) measured the gap formation rates in a temperate old-growth beech forest and found that they were five times higher than those measured in our study area; they proposed that the gap number increases with the increasing frequency of typhoon. (2) Endogenous senescence also drives gap formation, particularly in old-growth forests, though it is rare in secondary forests, where senescence typically produces small gaps (Diaci et al. 2012). (3) Forest age affects tree growth rates. The gap closure process is largely controlled by lateral

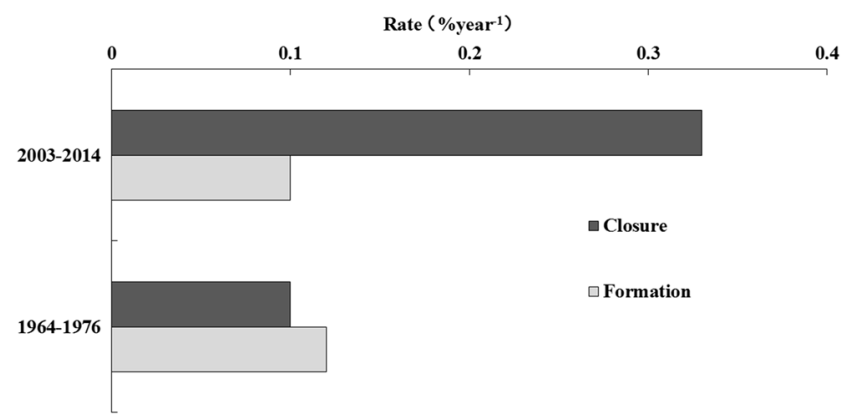

Fig. 4 Formation rate, closure rate and turnover rate of gaps in the periods of 1964-1976 and 2003-2014 


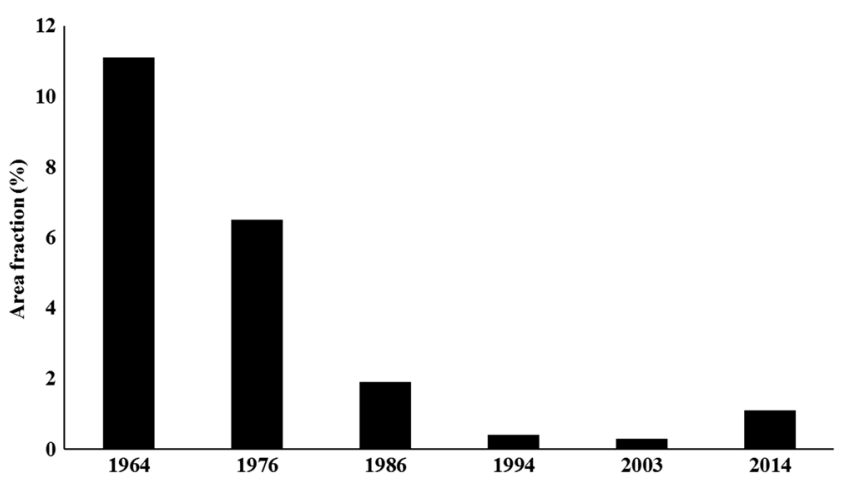

Fig. 5 Areal fraction of large opening in different observation years

extension growth, and tree growth rates in older forests are usually lower than those in younger stands (Rugani et al. 2013). (4) Different rates of gap formation and closure might be a function of differences in the durations of observation periods. Fujita et al. (2003) compared gap formation rates detected by analyses of aerial photographs at the same study site, with 5-year and 17year observation intervals. The gap formation estimate with a 17year interval was three times higher than the estimate for a 5-year interval. To some extent, these potential explanations account for our distinctive results of gap dynamics in a temperate secondary forest. We provide additional evidence for the diversity of canopy gap dynamics in temperate forests, as reported by Manabe et al. (2009).

The durations of large and medium gaps in the temperate secondary forest at our study site was 30-40 years, respectively, which was similar to those reported by Diaci et al. (2012) for a temperate old-growth forest, where the gaps $\left(200-300 \mathrm{~m}^{2}\right)$ required 30-60 years for canopy closure, but remarkably shorter than the gap duration of 50-100 years in the boreal forest studied by Vepakomma et al. (2012). The particular gap duration time at our site may be related to at least three factors, i.e., regeneration growth rate, canopy height, and the presence of advanced regeneration. First, trees in temperate forests usually grow faster than those in boreal stands because of the higher temperature and light levels associated with high solar angles at lower latitudes (Gray et al. 2012). The relatively long growing season in the temperate forest may be another reason for a high annual average regeneration growth rate (Littell et al. 2008). Second, canopy height also determines gap infilling because the higher the canopy is, the longer the period to gap closure (Vepakomma et al. 2011). In a boreal forest studied by Vepakomma et al. (2012), the canopy height was $40 \mathrm{~m}$, almost double the average canopy height in our secondary forest. The canopy height differences had predictable

Table 4 Gap fraction, mean gap size, gap formation rates (GFR) and gap closure rates (GCR) in different forest types

\begin{tabular}{|c|c|c|c|c|c|c|c|}
\hline Reference & Location & Forest type & $\begin{array}{l}\text { Gap } \\
\text { fraction } \\
(\%)\end{array}$ & $\begin{array}{l}\text { Mean gap } \\
\text { size }\left(\mathrm{m}^{2}\right)\end{array}$ & $\begin{array}{l}\text { GFR } \\
\left(\% \text { year }^{-1}\right)\end{array}$ & $\begin{array}{l}\text { GCR } \\
\left(\% \text { year }^{-1}\right)\end{array}$ & $\begin{array}{l}\text { Duration of observation } \\
\text { period (years) }\end{array}$ \\
\hline $\begin{array}{l}\text { Foster and Reiners } \\
\text { (1986) }\end{array}$ & USA & Old-growth coniferous & 33 & - & 0.3 & - & 1 \\
\hline $\begin{array}{l}\text { Liu and Hytteborn } \\
\text { (1991) }\end{array}$ & Sweden & Old-growth coniferous & 31 & 84.2 & $0.4-0.5$ & & 1 \\
\hline Henbo et al. (2006) & Japan & Old-growth coniferous & 15.1 & 98 & 0.1 & 0.4 & 42 \\
\hline $\begin{array}{l}\text { Kathke and } \\
\text { Bruelheide (2010) }\end{array}$ & Germany & Near-natural coniferous & $4.9-8.4$ & $212.7-479.9$ & 0.1 & 0.3 & 58 \\
\hline $\begin{array}{l}\text { Holeksa and } \\
\text { Cybulski (2001) }\end{array}$ & Poland & Near-natural coniferous & $27.4-33.8$ & 92 & $0.1-0.2$ & & 13 \\
\hline Runkle (1982) & USA & $\begin{array}{l}\text { Old-growth mixed } \\
\text { broadleaf-conifer forest }\end{array}$ & 9.5 & $28-69$ & 1 & 1 & 1 \\
\hline Henbo et al. (2004) & Japan & $\begin{array}{l}\text { Old-growth broadleaved } \\
\text { forest }\end{array}$ & $10.7-23.0$ & $88.4-223.1$ & $0.5-1.3$ & $0.3-0.5$ & 43 \\
\hline Blackburn (2014) & England & $\begin{array}{l}\text { Nesar-natural broadleaved } \\
\text { deciduous forests }\end{array}$ & 23.5 & 237 & 0.9 & 0.6 & 10 \\
\hline $\begin{array}{l}\text { Tanaka and } \\
\text { Nakashizuka } \\
\text { (1997) }\end{array}$ & Japan & $\begin{array}{l}\text { Old-growth broadleaved } \\
\text { deciduous forest }\end{array}$ & $5.5-11.0$ & $79.4-116.1$ & $0.4-1.1$ & $0.2-1.1$ & 50 \\
\hline Rugani et al. (2013) & Slovenia & $\begin{array}{l}\text { Old-growth broadleaved } \\
\text { deciduous forest }\end{array}$ & $3.2-10.6$ & $118-317$ & $0.2-0.3$ & $0.1-0.2$ & $11-20$ \\
\hline $\begin{array}{l}\text { Kenderes et al. } \\
\text { (2008) }\end{array}$ & Hungary & $\begin{array}{l}\text { Old-growth broadleaved } \\
\text { deciduous forest }\end{array}$ & $2.5-7.7$ & $40-93$ & $0.2-0.3$ & 0.1 & 30 \\
\hline Fujita et al. (2003) & Japan & $\begin{array}{l}\text { Old-growth broadleaved } \\
\text { evergreen forest }\end{array}$ & $10.9-13.6$ & $104-138$ & $0.3-1.0$ & $0.3-0.7$ & 32 \\
\hline Bottero et al. (2011) & $\begin{array}{l}\text { Bosnia and } \\
\text { Herzegovina }\end{array}$ & $\begin{array}{l}\text { Old-growth mixed } \\
\text { broadleaf-conifer forest }\end{array}$ & 19.3 & 76.9 & & & 1 \\
\hline Our research (gaps) & China & $\begin{array}{l}\text { Secondary broadleaved } \\
\text { deciduous forest }\end{array}$ & $2.6-5.1$ & $74-129$ & 0.1 & $0.1-0.4$ & 50 \\
\hline
\end{tabular}


Fig. 6 Closing process of newly formed large gaps and medium gaps in the following years, after they appeared in different observation intervals. $F$ Forest, $G$ gap, $N L$-Total number of newly formed large gaps, NM-Total number of newly formed medium gaps, $N L-F$ number of large gaps that transformed to forest at each following time period, $N M-F$ number of medium gaps that transformed to forest at each following time period

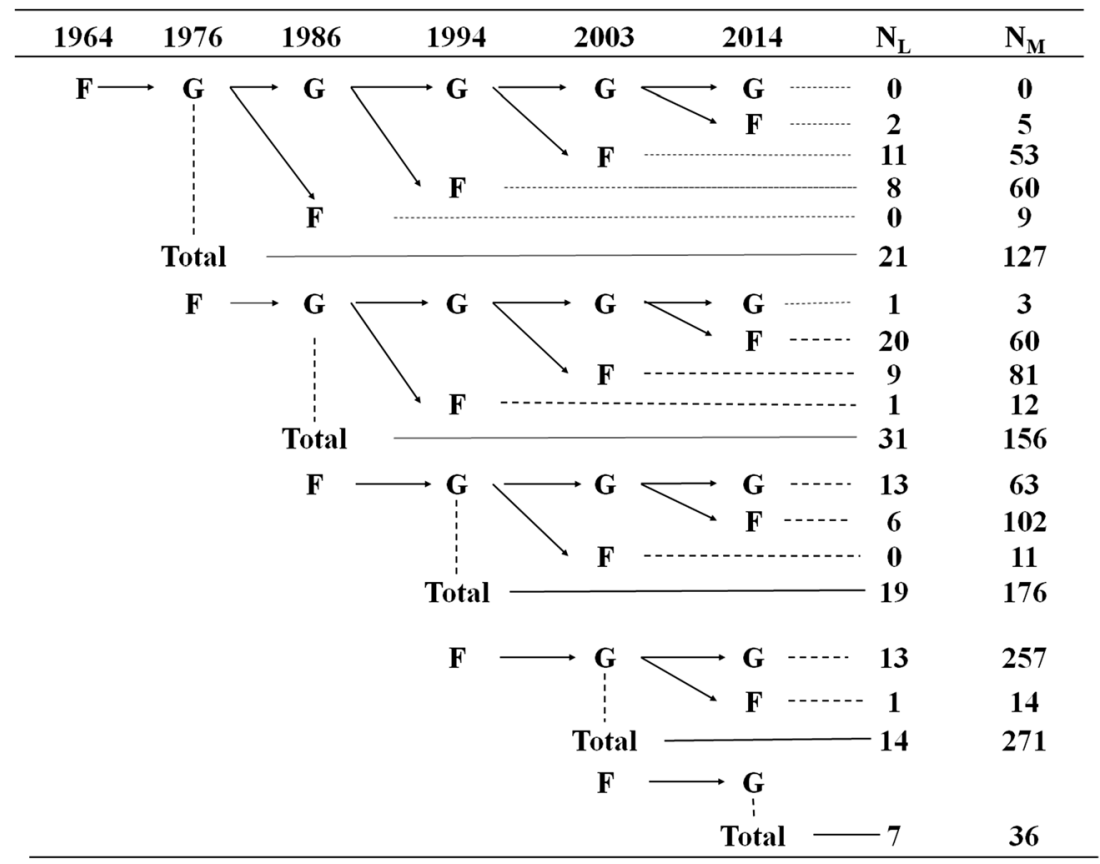

effects on gap duration times. Third, the short gap duration at our site may have been related to the relatively high advanced regeneration capacity associated with the relatively complex structure of the temperate forest. Species with advanced regeneration capabilities have advantages in the competition for resources over species that regenerate from seeds when gaps form; advanced regeneration capacity accelerates the closure of gaps (Felton et al. 2006). These explanations partly account for the relatively short gap duration times in the temperate secondary forest we studied.

In our study area, $80 \%$ of the large openings that existed in 1964 were infilled by artificial plantations by 1994. In a similar study of large-opening restoration conducted by NadalRomero et al. (2013), most of the large openings were still open after more than 50 years of secondary plant succession. The inconsistency among studies can be largely attributed to differences in anthropogenic influence. In northeastern China, afforestation programs on large openings were implemented by the National Forest Service between the 1960s and 1990s to promote timber production (Wang 2007). Tree seedlings were planted in large openings and tended with appropriate husbandry measures, such as shrub cutting, soil preparation, etc. With these procedures in place, the infilling process in large openings began with artificial young tree recruitment, skipping stages of invasion by herbaceous plants and woody shrubs. Regular thinning management decreased intra-specific competition and further accelerated the growth of young trees (Schulze 2008), so that the large openings in our study area were quickly infilled with forest over a 30 -year period.
The objective of forest management for secondary forests is to restore a mature forest. The baseline data on past and current gap dynamics in this study may prove useful to the management of secondary forests. Our findings demonstrated that the secondary forest had obviously lower gap dynamic parameters than temperate old-growth forests, such as gap size. Although the gap partitioning hypothesis (Holladay et al. 2006) considers smaller gaps or intact forest to be favorable to the establishment and survival of shade-tolerant species, it may take a long time for shade-tolerant species to reach the forest canopy because of the limited growth space. We previously identified the effects of gaps on regeneration of woody plants by meta-analysis of 42 publications and found that gaps with higher light intensity also exhibited a positive effect $(+124 \%)$ on the regeneration of shade-tolerant species (Zhu et al. 2014); sufficient growing space seemed to offset, or even outweigh, this disadvantage (Poorter 2009). Thus, for forest managers, we suggested that simulating gap disturbance accompanied by supporting measures, such as cutting shrubs and planting, should be applied to accelerate the succession of secondary forests.

\section{Conclusions}

The gap dynamics in the secondary forest studied over the period of 1964-2014 were comparable to those of other temperate forests. The time required to close $100 \%$ of the medium 
or large gaps was $30-40$ years, although the cumulative proportion of closed medium gaps was quite high after only 20 years. Our observations improve the understanding of gap turnover rates in secondary forests affected by natural disturbances and can be used to assess the current status, and estimate canopy turnover rates, of forests.

Acknowledgments We thank Dr. Tao Yan from Institute of Applied Ecology, Chinese Academy. We also thank the editors of Annals of Forest Science and the anonymous reviewers for their valuable criticisms, suggestions and the detail revisions on our manuscript.

Funding information This study was financially supported by National Natural Science Foundation of China (31330016, 41371511).

Data availability The datasets generated during the current study are available from the corresponding author on reasonable request.

\section{Compliance with ethical standards}

Conflict of interest The authors declare that they have no conflict of interest.

\section{References}

Bartemucci P, Coates KD, Harper KA, Wright EF (2002) Gap disturbances in northern old-growth forests of British Columbia, Canada. J Veg Sci 13:685-696. https://doi.org/10.1111/j.16541103.2002.tb02096.x

Baumann M, Ozdogan M, Wolter PT, Krylov A, Vladimirova N, Radeloff VC (2014) Landsat remote sensing of forest windfall disturbance. Remote Sens Environ 143:171-179. https://doi.org/10. 1016/j.rse.2013.12.020

Blackburn GA (2014) Forest disturbance and regeneration: amosaic of discrete gap dynamics and openmatrix regimes? J Veg Sci 25:13411354. https://doi.org/10.1111/jvs.12201

Bottero A, Garbarino M, Dukic V, Govedar Z, Lingua E, Nagel TA, Motta R (2011) Gap-phase dynamics in the old-growth Forest of Lom, Bosnia and Herzegovina. Silva Fennica 45:875-887

Diaci J, Adamic T, Rozman A (2012) Gap recruitment and partitioning in an old-growth beech forest of the Dinaric Mountains: influences of light regime, herb competition and browsing. For Ecol Manag 285: 20-28. https://doi.org/10.1016/j.foreco.2012.08.010

Elias RB, Dias E (2009) Gap dynamics and regeneration strategies in Juniperus-Laurus forests of the Azores Islands. Plant Ecol 200: 179-189. https://doi.org/10.1007/s11258-008-9442-x

Felton A, Felton AM, Wood J, Lindenmayer DB (2006) Vegetation structure, phenology, and regeneration in the natural and anthropogenic tree-fall gaps of a reduced-impact logged subtropical Bolivian forest. For Ecol Manag 235:186-193. https://doi.org/10.1016/j.foreco. 2006.08.011

Foster JR, Reiners WA (1986) Size distribution and expansion of canopy gaps in a northern Appalachian spruce-fir forest. Vegetatio 68:109114

Fujita T, Itaya A, Miura M, Manabe T, Yamamoto S-I (2003) Long-term canopy dynamics analysed by aerial photographs in a temperate old- growth evergreen broad-leaved forest. J Ecol 91:686-693. https:// doi.org/10.1046/j.1365-2745.2003.00796.x

Garbarino M, Borgogno Mondino E, Lingua E, Nagel TA, Dukić V, Govedar Z, Motta R (2012) Gap disturbances and regeneration patterns in a Bosnian old-growth forest: a multispectral remote sensing and ground-based approach. Ann For Sci 69:617-625. https://doi. org/10.1007/s13595-011-0177-9

Gray AN, Spies TA, Pabst RJ (2012) Canopy gaps affect long-term patterns of tree growth and mortality in mature and old-growth forests in the Pacific northwest. For Ecol Manag 281:111-120. https://doi. org/10.1016/j.foreco.2012.06.035

Henbo Y, Itaya A, Nishimura N (2004) Long-term canopy dynamics in a large area of temperate old-growth beech ( Fagus crenata ) forest: analysis by aerial photographs and digital elevation models. J Ecol 92:945-953. https://doi.org/10.1111/j.1365-2745.2004.00932.x

Henbo Y, Itaya A, Nishimura N, Yamamoto S-I (2006) Long-term canopy dynamics analyzed by aerial photographs and digital elevation data in a subalpine old-growth coniferous forest. Ecoscience 13:451-458

Holeksa J, Cybulski M (2001) Canopy gaps in a Carpathian subalpine spruce forest. Forstwiss Centralbl 120:331-348

Holladay C, Kwit C, Collins B (2006) Woody regeneration in and around aging southern bottomland hardwood forest gaps: effects of herbivory and gap size. For Ecol Manag 223:0-225

Kathke S, Bruelheide H (2010) Gap dynamics in a near-natural spruce forest at Mt. Brocken, Germany. For Ecol Manag 259:624-632. https://doi.org/10.1016/S0378-1127(00)00284-X

Kenderes K, Mihok B, Standovar T (2008) Thirty years of gap dynamics in a central European beech forest reserve. Forestry 81:111-123. https://doi.org/10.1093/forestry/cpn001

Landis JR, Koch GG (1977) The measurement of observer agreement for categorical data. Biometrics 33:159-174. https://doi.org/10.2307/ 2529310

Li X, Zhu J, Wang Q, Liu Z (2005) Forest damage induced by wind/snow: a review. Acta Ecol Sin 25:148-157

Littell JS, Peterson DL, Tjoelker M (2008) Douglas-fir growth in mountain ecosystems: water limits tree growth from stand to region. Ecol Monogr 78:349-368. https://doi.org/10.1890/07-0712.1

Liu QH, Hytteborn H (1991) Gap structure, disturbance and regeneration in a primeval picea-abies forest. J Veg Sci 2:391-402. https://doi. org/10.2307/3235932

Lu D, Zhu J, Sun Y, Hu L, Zhang G (2015) Gap closure process by lateral extension growth of canopy trees and its effect on woody species regeneration in atemperate secondary forest, Northeast China. Silva Fenn 49(5). https://doi.org/10.1016/j.foreco.2018.02.022

Manabe T, Shimatani K, Kawarasaki S, Aikawa SI, Yamamoto SI (2009) The patch mosaic of an old-growth warm-temperate forest: patchlevel descriptions of 40-year gap-forming processes and community structures. Ecol Res 24:575. https://doi.org/10.1007/s11284-0080528-7

Muscolo A, Bagnato S, Sidari M, Mercurio R (2014) A review of the roles of forest canopy gaps. J For Res 25:725-736. https://doi.org/ 10.1007/s11676-014-0521-7

Nadal-Romero E, Torri D, Yair A (2013) Updating the badlands experience. Catena 106:1-3. https://doi.org/10.1016/j.catena.2012.07.009

Petritan AM, Nuske RS, Petritan IC, Tudose NC (2013) Gap disturbance patterns in an old-growth sessile oak (Quercus petraea L.)European beech (Fagus sylvatica L.) forest remnant in the Carpathian Mountains, Romania. For Ecol Manag 308:67-75. https://doi.org/10.1016/j.foreco.2013.07.045

Poorter L (2009) Leaf traits show different relationships with shade tolerance in moist versus dry tropical forests. New Phytol 181:890-900 
Raymond P, Munson A, Ruel J (2006) Spatial patterns of soil microclimate, light, regeneration, and growth. Can J For Res 36:639-651

Ritter E, Dalsgaard L, Einhorn K (2005) Light, temperature and soil moisture regimes following gap formation in a semi-natural beechdominated forest in Denmark. For Ecol Manag 206:15-33

Rugani T, Diaci J, Hladnik D (2013) Gap dynamics and structure of two old-growth beech forest remnants in Slovenia. PLoS One 8:e52641. https://doi.org/10.1371/journal.pone.0052641

Runkle JR (1982) Patterns of disturbance in some old-growth Mesic forests of eastern North America. Ecol 63:1533-1546. https://doi. org/10.2307/1939997

Runkle JR (1989) Synchrony of regeneration, gaps, and latitudinal differences in tree species-diversity. Ecology 70:546-547

Sapkota P, Tigabu M, Odén PC (2009) Species diversity and regeneration of old-growth seasonally dry Shorea robusta forests following gap formation. J For Res 20:7-14

Schulze M (2008) Technical and financial analysis of enrichment planting in logging gaps as a potential component of forest management in the eastern Amazon. For Ecol Manag 255:866-879. https://doi.org/ 10.1016/j.foreco.2007.09.082

Sefidi K, Mohadjer MR, Mosandl R (2011) Canopy gaps and regeneration in old-growth oriental beech (Fagus orientalis, Lipsky) stands, northern Iran. For Ecol Manag 262:1094-1099

Tanaka H, Nakashizuka T (1997) Fifteen years of canopy dynamics analyzed by aerial photographs in a temperate deciduous forest, Japan. Ecology 78:612-620. https://doi.org/10.1890/0012-9658(1997) 078[0612:FYOCDA]2.0.CO;2

Vepakomma U, St-Onge B, Kneeshaw D (2008) Spatially explicit characterization of boreal forest gap dynamics using multi-temporal lidar data. Remote Sens Environ 112:2326-2340

Vepakomma U, Kneeshaw D, Fortin M-J (2012) Spatial contiguity and continuity of canopy gaps in mixed wood boreal forests: persistence, expansion, shrinkage and displacement. J Ecol 100:1257-1268. https://doi.org/10.2307/23257547

Vepakomma U, St-Onge B, Kneeshaw D (2011) Response of a boreal forest to canopy opening: assessing vertical and lateral tree growth with multi-temporal lidar data. Ecol Appl 21:99-121
Wang W (2007) The forest resources in Liaoning Province. China Forestry, Beijing

Watt AS (1947) Pattern and process in the plant community. J Ecol 35:122

Yamamoto SI, Nishimura N, Torimaru T, Manabe T, Itaya A, Becek K (2011) A comparison of different survey methods for assessing gap parameters in old-growth forests. For Ecol Manag 262:886-893. https://doi.org/10.1016/j.foreco.2011.05.029

Yan Q, Zhu J, Zhang J, Yu L, Hu Z (2010) Spatial distribution pattern of soil seed bank in canopy gaps of various sizes in temperate secondary forests, Northeast China. Plant Soil 329:469-480. https://doi. org/10.1007/s11104-009-0172-1

Yan Q, Zhu J, Hu Z, Sun O (2011) Environmental impacts of the shelter forests in Horqin sandy land, Northeast China. J Environ Qual 40: 815. https://doi.org/10.2134/jeq2010.0137

Zhu J, Mao Z, Hu L, Zhang J (2007) Plant diversity of secondary forests in response to anthropogenic disturbance levels in montane regions of northeastern China. J For Res 12:403-416. https://doi.org/10. 1007/s10310-007-0033-9

Zhu J, Lu D, Zhang W (2014) Effects of gaps on regeneration of woody plants: a meta-analysis. J For Res 25:501-510

Zhu J, Zhang G, Wang GG, Yan Q, Lu D, Li X, Zheng X (2015) On the size of forest gaps: can their lower and upper limits be objectively defined? Agr For Meteor 213:64-76. https://doi.org/10.1016/j. agrformet.2015.06.015

Zhu C, Zhu J, Zheng X, Lu D, Li X (2017) Comparison of gap formation and distribution pattern induced by wind/snowstorm and flood in a temperate secondary forest ecosystem, Northeast China. Silva Fenn 51(5). https://doi.org/10.14214/sf.7693

Publisher's note Springer Nature remains neutral with regard to jurisdictional claims in published maps and institutional affiliations. 